Article

\title{
Single Amino Acid Substitutions in the Cucumber Mosaic Virus 1a Protein Induce Necrotic Cell Death in Virus-Inoculated Leaves without Affecting Virus Multiplication
}

\author{
Ainan Tian, Shuhei Miyashita $₫$, Sugihiro Ando and Hideki Takahashi * \\ Graduate School of Agricultural Science, Tohoku University, 468-1, Aramaki-Aza-Aoba, Sendai 980-0845, Japan; \\ imtenten@me.com (A.T.); shuhei27@gmail.com (S.M.); sugihiro.ando.a2@tohoku.ac.jp (S.A.) \\ * Correspondence: hideki.takahash.d5@tohoku.ac.jp; Tel.: +81-81227574300
}

Received: 4 October 2019; Accepted: 9 January 2020; Published: 13 January 2020

\begin{abstract}
When Arabidopsis thaliana ecotype Col-0 was inoculated with a series of reassortant viruses created by exchanging viral genomic RNAs between two strains of cucumber mosaic virus (CMV), $\mathrm{CMV}(\mathrm{Y})$, and $\mathrm{CMV}(\mathrm{H})$, cell death developed in the leaves inoculated with reassortant $\mathrm{CMV}$ carrying $\mathrm{CMV}(\mathrm{H}) \mathrm{RNA1}$ encoding 1a protein, but not in noninoculated upper leaves. In general, cell death in virus-infected plants is a critical event for virus survival because virus multiplication is completely dependent on host cell metabolism. However, interestingly, this observed cell death did not affect either virus multiplication in the inoculated leaves or systemic spread to noninoculated upper leaves. Furthermore, the global gene expression pattern of the reassortant CMV-inoculated leaves undergoing cell death was clearly different from that in hypersensitive response (HR) cell death, which is coupled with resistance to CMV. These results indicated that the observed cell death does not appear to be HR cell death but rather necrotic cell death unrelated to CMV resistance. Interestingly, induction of this necrotic cell death depended on single amino acid substitutions in the $\mathrm{N}$-terminal region surrounding the methyltransferase domain of the 1a protein. Thus, development of necrotic cell death might not be induced by non-specific damage as a result of virus multiplication, but by a virus protein-associated mechanism. The finding of CMV 1a protein-mediated induction of necrotic cell death in A. thaliana, which is not associated with virus resistance and HR cell death, has the potential to provide a new pathosystem to study the role of cell death in virus-host plant interactions.
\end{abstract}

Keywords: cell death; cucumber mosaic virus; hypersensitive response; methyltransferase domain; necrosis

\section{Introduction}

The role of cell death in virus-host plant interactions is a phenomenon that has long been discussed but has yet to be resolved [1-5]. Cell death in virus-infected plants is a critical event for the survival of the virus because virus multiplication is completely dependent on host cell metabolism. Cell death resulting from incompatible interactions between viruses and plants has been described as necrotic local lesions, and that occurring in compatible interactions as necrotic cell death [6,7]. Cell death observed as necrotic local lesions at primary viral infection sites on host plants that carry nucleotide-binding and leucine-rich repeat (NB-LRR) class R protein-coding virus resistance $(R)$ genes, and infected with a virus carrying avirulence $(A V R)$ gene encoding AVR protein, has been thoroughly analyzed: it has long been recognized as a hallmark of the hypersensitive response (HR) and R protein-mediated resistance to viruses [8-11]. Thus, cell death which develops at necrotic local lesions, is referred to as $H R$ cell death. Also, it is now considered a form of programmed cell death (PCD) due to similarities 
in the cytological and physiological features of this kind of cell death between plants and animals, despite some substantial differences; for example, while plant PCD exhibits vacuolar death, animal PCD does not [11-14]. Thus, HR cell death has been well characterized. However, while HR cell death should be critical for virus multiplication, viruses are still able to move into the living cells surrounding the necrotic local lesions, and prevention of the further spread of viruses into living cells surrounding necrotic local lesions is observed [15-18]. Thus, the role of HR cell death in virus resistance is still unclear.

In comparison with HR cell death, necrotic cell death seems to be poorly understood, although a limited number of studies have been reported. For example, cucumber mosaic virus (CMV)-induced cell death was observed on inoculation of $A$. thaliana leaves with a lily strain of CMV [CMV(HL)], and it was concluded that this necrotic cell death was caused by reduction of host catalase activity through direct interaction between $\mathrm{CMV}(\mathrm{HL}) 2 \mathrm{~b}$ protein and catalase, thereby preventing production of scavenging cellular hydrogen peroxide and resulting in necrotic cell death [19]. However, it remains unclear if necrotic cell death resulted from non-specific damage to host cells caused by CMV(HL) infection, rather than as a form of programmed cell death. Other than the necrotic cell death that has been investigated, various types of necrotic cell death that are not well characterized seem to exist in various interactions between host plants and viruses [7].

CMV is one of the best characterized tripartite RNA viruses and has positive-sense single-stranded RNA genomes: RNA1, RNA2, and RNA3 [20]. RNA1 encodes the 1a protein, which has two putative functional domains: a methyltransferase (MET) domain in amino acid positions 72-290 and a helicase/NTP-binding (HEL) domain in amino acid positions 711-976 [21,22]. RNA2 encodes the 2a protein containing motifs of RNA-dependent RNA polymerase [22]. The 1a protein interacts with the 2a protein through the HEL domain in the yeast-two hybrid system [23] and these are thought to be components of a viral replicase complex [24]. RNA2 has a second open reading frame (ORF) encoding the $2 b$ protein, which functions as a suppressor of post-transcriptional gene silencing (PTGS) [25-28]. RNA3 has two open reading frames: 3a and coat protein (CP) [29-31]. 3a encodes a cell-to-cell movement protein (3a protein). CP is translated from subgenomic RNA4, which is generated from the CP region of minus-stranded RNA3 in virus-infected cells. CMV has a large host range including Arabidopsis thaliana [20], and comparative and incompatible interactions between CMV strains and A. thaliana ecotypes have been well characterized at the molecular level [32].

Interestingly, in analysis of the host response to a series of reassortant viruses between two CMV strains with differing virulence in Arabidopsis thaliana, we discovered that cell death occurred in virus-inoculated leaves of $A$. thaliana ecotype Col-0 in response to a reassortant CMV. In the present study, this cell death phenomenon is characterized, and the viral determinant inducing cell death is identified. Several features of the cell death observed here indicated that it might not be HR cell death but rather necrotic cell death that does not affect CMV multiplication. Development of this necrotic cell death is determined by single amino acid residues in the N-terminal region surrounding the methyltransferase domain of the 1a protein encoded on CMV RNA1.

\section{Materials and Methods}

\subsection{Plants and Virus}

Arabidopsis thaliana ecotype Col-0 and other 94 ecotypes are listed in Table S1. RCY1-transformed Col-0 (Col::pRCY1-HA\#12) [33] which is renamed Col::RCY1 in the present study, and Nicotiana benthamiana were grown on soilless mix (Metro-Mix ${ }^{\circledR} 380$, Sun Gro Horticulture, Agawam, MA, USA) under a 14-h light (14,000 lux)/10-h dark photoperiod at $25^{\circ} \mathrm{C}$ in a KG-201 HL-D growth chamber (Koito, Yokohama, Japan). Since RCY1 was isolated from A. thaliana ecotype C24 as a NB-LRR class resistance gene to a yellow strain of CMV $[\mathrm{CMV}(\mathrm{Y})], \mathrm{Col}: \mathrm{RCY} 1$ was used as a control for developing HR cell death in response to CMV [33,34]. CMV(Y) [35] and the H strain of cucumber mosaic virus $[\mathrm{CMV}(\mathrm{H})]$, which was isolated from an Arabidopsis halleri plant showing no symptoms, were used for 
these experiments. Also used were a series of reassortant CMVs exchanging RNA1, 2, and 3 between $\mathrm{CMV}(\mathrm{Y})$ and $\mathrm{CMV}(\mathrm{H})$; $\mathrm{CMV}$ carrying chimeric RNA1 between $\mathrm{CMV}(\mathrm{Y})$ and $\mathrm{CMV}(\mathrm{H})$ and $\mathrm{CMV}(\mathrm{Y})$; and CMV carrying single amino acid substitutions in $\mathrm{CMV}(\mathrm{Y})$ 1a protein encoded in CMV RNA1.

\subsection{In Vitro Transcription of Infectious CMV RNA and Production of Reassortant CMV}

Infectious CMV(Y) RNA1, RNA2, and RNA3 were transcribed in vitro pCY1-T7, pCY2-T7, and pCY3-T7, respectively [36]. cDNAs of CMV(H) RNA1, 2, and 3 were synthesized by RT-PCR according to standard protocol [37], with the following sets of primers: CMV.RNA1-5'.F and CMV.RNA1-3'.R for RNA1; CMV.RNA2-5'.F and CMV.RNA2-3' ${ }^{\prime}$.R for RNA2; and CMV.RNA3-5'.F and CMV.RNA3-3'.R for RNA3 (Table S2). The sequence encoding T7 RNA polymerase was included in primers CMV.RNA1-5'.F, CMV.RNA2-5' 'F, and CMV.RNA3-5'.F (Table S2). RT-PCR reactions were performed using the PrimeScript ${ }^{\mathrm{TM}}$ II High Fidelity One Step RT-PCR Kit (Takara Bio, Shiga, Japan) according to the manufacturer's instructions. All PCR products were purified with the Wizard ${ }^{\circledR}$ SV Gel and PCR Clean-Up System (Promega, Madison, WI, USA). The gel-purified cDNA of RNA1 was cloned into the HindIII and NotI sites of pUC118 (Takara Bio) and the cDNAs of RNA2 and RNA3 were cloned into the BamHI and NotI sites using the In-Fusion HD Cloning System (Takara Bio) according to the manufacturer's instructions. The plasmid constructs containing each of the CMV(H) RNA1, RNA2, and RNA3 cDNAs (designated pCH1-T7, pCH2-T7, and pCH3-T7, respectively) were linearized by digestion with NotI and purified using the Wizard ${ }^{\circledR}$ SV Gel and PCR Clean-Up System (Promega). Each linearized plasmid DNA was then transcribed in vitro using T7 RNA polymerase with the standard AmpliCap-Max ${ }^{\mathrm{TM}}$ T7 High Yield Message Maker Kit (Cellscript, Madison, WI, USA) according to the manufacturer's instructions.

To generate the reassortant CMVs including CMV(HYY), CMV(YHY), CMV(YHH), CMV(YYH), $\mathrm{CMV}(\mathrm{HYH})$, and CMV(HHY) (Figure S1), each infectious CMV RNA1, RNA2, and RNA3 was reciprocally exchanged between $\mathrm{CMV}(\mathrm{Y})$ and $\mathrm{CMV}(\mathrm{H})$. Four-week-old N. benthamiana was rub-inoculated with a combination of infectious $\mathrm{CMV}(\mathrm{Y})$ and $\mathrm{CMV}(\mathrm{H}) \mathrm{RNA1}$, RNA2, and RNA3 to propagate a series of reassortant CMVs. At 7 days post-inoculation (dpi), the inoculated leaves were collected and weighed, and then ground in $10 \times$ volume of $0.1 \mathrm{M}$ phosphate-buffered saline $(\mathrm{pH}$ 8.0) on ice. These homogenates were used to inoculate new fully expanded leaves of 6-week-old $N$. benthamiana plants. At $4 \mathrm{dpi}$, the inoculated leaves were harvested and used for virus purification. Virus purification was performed according to a previously described procedure [38].

\subsection{Virus Inoculation and Detection}

Fully expanded leaves of $A$. thaliana were rub-inoculated with $100 \mu \mathrm{g} / \mathrm{mL}$ of virus as previously described [39]. Virus was detected immunologically by western blot analysis according to the standard protocol [37] using antibody against the CP of CMV.

Accumulation of CMV RNA in virus-inoculated leaves of Col-0 was analyzed by northern hybridization according to the standard protocol [37]. CMV RNA-specific cDNA probes complementary to the $3^{\prime}$ noncoding region of all CMV RNAs were amplified from CMV(Y) RNA3 CDNA with a pair of primers: $5^{\prime}$-GTGAACGGGTTGTCCATCCA-3' and 5'-ACCCTGAAACTAGCACGTTGT-3' by PCR. The probe cDNA was labeled with digoxigenin (DIG)-11-dUTP using a DIG PCR labeling kit (Roche, Penzberg, Germany) according to the manufacturer's instructions. The PCR product was purified according to the procedure of Takahashi and Ehara [38]. Ribosomal RNA (rRNA)-specific probe was obtained as described previously [33]. All CMV RNAs were detected using an alkaline phosphatase conjugated anti-DIG antibody (Roche, Penzberg, Germany) and visualized with the CDP-Star Reagent (New England Biolabs, Beverly, MA, USA) according to the manufacturer's protocols.

After $A$. thaliana ecotype Col-0 was inoculated with CMV containing chimeric RNA1 or RNA1 carrying a nucleotide substitution, all of the chimeric RNA1 cDNAs and single nucleotide substitution RNA1 cDNAs were amplified by RT-PCR from the upper noninoculated leaves of inoculated plants. RT-PCR-amplified fragments were purified by treatment with ExoSAP-IT PCR Clean Up Reagents 
(Thermo Fisher Scientific, Waltham, MA, USA) according to the instruction manual, and their nucleotide sequences were confirmed by Sanger sequencing using a CEQ8000 Automated DNA Sequencer (Beckman Coulter, Brea, CA, USA).

\subsection{Virus Quantification by ELISA}

For quantitative measurement of the CMV CP by ELISA, three independent virus-inoculated leaves were homogenized in a $10 \times$ volume of $0.01 \mathrm{M}$ potassium phosphate buffer $(\mathrm{pH} 8.0)$. The protein concentrations of the homogenates were determined using the Bradford reagent [39]. The homogenates used for ELISA were adjusted to $0.03 \mathrm{mg} / \mathrm{mL}$ total protein with $0.01 \mathrm{M}$ potassium phosphate buffer. CP quantities were measured using the method of Koenig (1981) [40] and expressed as the absorbance at $405 \mathrm{~nm}$ per $0.03 \mathrm{mg} / \mathrm{mL}$ of total protein. Statistical analysis of $\mathrm{CP}$ quantities were performed using one-way analysis of variance (ANOVA) and Fisher's least significant difference LSD test for post-hoc comparisons using IBM SPSS Statistics version 25 (IBM, Armonk, NY, USA).

\subsection{Detection of Cell Death}

Cell death in CMV-inoculated leaves was visualized by staining with trypan blue according to a standard protocol [41]. Virus-inoculated leaves were stained by boiling for $8 \mathrm{~min}$ in alcoholic lactophenol [99.5\% ethanol:phenol:glycerol:lactic acid 4:1:1:1 (v:v:v:v)] containing $0.1 \mathrm{mg} / \mathrm{mL}$ trypan blue. The stained leaves were decolorized in a $2.5 \mathrm{~g} / \mathrm{mL}$ chloral hydrate solution overnight, and then held and pictured in $70 \%$ ethanol. Trypan blue staining is available to detect cell death qualitatively, but it has limitations in attempting to show a quantitative measure of cell death.

\subsection{RNA-Seq Analysis}

Three independent mock- and CMV(HYY)-inoculated Col-0 leaves showing necrotic cell death at 5 dpi and mock- and $C M V(Y)$-inoculated Col::RCY1 leaves showing HR cell death at 3 dpi were used for extraction of total RNAs with the RNeasy Plant Mini Kit (Qiagen GmbH, Hilden, Germany). cDNA libraries were prepared using the TruSeq Stranded Total RNA with Ribo-Zero Plant Kit (Illumina, San Diego, CA, USA) according to the manufacturer's instructions. Approximately $2.7-3.9 \times 10^{5}$ paired-end reads $(75-b p \times 2)$ were obtained for each sample using the Illumina MiSeq (Illumina). The raw sequence data were submitted to the NCBI Gene Expression Omnibus under accession number GSE137625. The sequence reads were processed using Trimmomatic version 0.38 (Am Mühlenberg, Altenau, Germany) [42] for adaptor trimming and quality filtering. The processed reads were mapped to the genome sequences of $A$. thaliana ecotype Col-0, $\mathrm{CMV}(\mathrm{Y})$, and $\mathrm{CMV}(\mathrm{H})$ using STAR version 2.7 (New York, NY, USA) [43] at default settings. Read counts per $A$. thaliana gene were retrieved using the quantification option in STAR, and were normalized and statistically tested using DESeq $2 \mathrm{R}$ package 3.7 (Boston, MA, USA) [44]. Adjusted $p$-values were calculated [45], and the threshold-adjusted $p$-value was set to 0.05 for the present study. Independent filtering in DESeq2 with an automatically optimized threshold was performed to filter out the genes with low mean normalized counts. Genes that passed independent filtering in both the necrotic cell death versus mock and HR cell death versus mock comparisons were further analyzed for differential expression. Genes with fold-change $>4$ or $<0.25$ at an adjusted $p$-value of $<0.05$ were considered to be differentially expressed genes (DEGs). DEGs with increased expression unique to HR cell death were classified as Class I; DEGs with commonly increased expression in HR cell death and necrotic cell death were classified as Class II; and DEGs with increased expression unique to necrotic cell death were classified as Class III. DEGs with decreased expression unique to HR cell death were classified as Class IV; DEGs with commonly decreased expression in HR cell death and necrotic cell death were classified as Class V; and DEGs with decreased expression unique to necrotic cell death were classified as Class VI. The VennDiagram package (Toronto, Ontario, Canada) [46] was used to generate Venn diagrams of the sets of DEGs that overlapped between HR cell death and necrotic cell death. Gene symbols and gene ontology (GO) information were extracted using Metascape (http://metascape.org/gp/index.html) (accessed on 11th, January, 2020) [47]. GO enrichment 
analysis was implemented using ClusterProfiler package 3.14.0 (Guangzhou, Guangdong, China) in R software for the DEGs in each class [48].

\subsection{Construction of In Vitro Transcription Vectors Carrying Chimeric cDNA of CMV RNA1}

In vitro transcription vectors carrying chimeric forms of the region encoding the 1a protein in the RNA1 cDNA of $\mathrm{CMV}(\mathrm{H})$ or $\mathrm{CMV}(\mathrm{Y})$ were constructed as described below to generate vectors $\mathrm{Y}-\mathrm{H} / 683$, $\mathrm{H}-\mathrm{Y} / 683$ (Figure 7A); Y-H/343 and Y-H/344 682 (Figure 8A); and then vectors Y-H/71, Y-H/72 343, Y-H/290, Y-H/72 290, Y-H/71 + 291 343, and Y-H/291 343 (Figure 9A). All chimeric forms of the RNA1 cDNA region encoding 1a protein were generated by two-step PCR. First, the $3^{\prime}$ - and 5'-fragments of RNA1 cDNA were amplified using $\mathrm{CMV}(\mathrm{H})$ or $\mathrm{CMV}(\mathrm{Y})$ cDNA as a template with the primers CMV RNA1-5'.FOR (Table S3) and an internal reverse primer based on the reverse-strand sequence of the junction site for chimeric constructs (Table S3). Secondary PCR products were also amplified using an additional internal forward primer complementary to the reverse primer (Table S3) and the CMV.RNA1-3'.REV primer (Table S3) used in the primary PCR. In some instances, such as for vectors Y-H/71, Y-H/72 343, Y-H/290, Y-H/72 290, Y-H/71 + 291 343, and Y-H/291 343 (Figure 9A), tertiary internal fragments were also amplified by RT-PCR using another set of internal primers. The sets of internal PCR primers used are listed in Table S3.

In the second round of PCR, the resulting $5^{\prime}$ and $3^{\prime}$ fragments of RNA 1 cDNA (and a third internal RT-PCR fragment, when necessary) amplified in the first PCR were used as templates to produce full-length chimeric RNA1 cDNA by PCR using the primers CMV.RNA1-5'.F and CMV.RNA1-3'.R (Table S2). All PCR products were purified using the Wizard ${ }^{\circledR}$ SV Gel and PCR Clean-Up System (Promega). The gel-purified RNA1 cDNA fragment was cloned into the HindIII and NotI sites of pUC118 (Takara Bio) with the In-Fusion HD Cloning System (Takara Bio) according to the manufacturer's instructions. The nucleotide sequences of vector constructs carrying chimeric CMV RNA1 cDNAs were confirmed by Sanger sequencing using a CEQ8000 Automated DNA Sequencer (Beckman Coulter).

\subsection{Single Amino Acid Substitution in 1a Proteins Encoded on RNA1 of CMV(Y)}

Amino acid substitutions in the 1a protein were performed by generating site-directed mutant cDNAs by nucleotide substitution in pCY1-T7 using the GENEART Site-Directed Mutagenesis System (Thermo Fisher Scientific) with primers designed according to the manufacturer's instructions. The primers used for nucleotide substitution are shown in Table S4. All constructs were confirmed by Sanger sequencing using a CEQ8000 Automated DNA Sequencer (Beckman Coulter). In vitro transcription vectors carrying nucleotide substitutions in the 1a protein-coding region of the $\mathrm{CMV}(\mathrm{Y})$ RNA1 cDNA were designated T29A, I49V, G54S, R298Q, G299R, and H310N (Figure 10A).

\section{Results}

\subsection{Response of Arabidopsis thaliana Ecotype Col-0 to a Series of Reassortant CMVs}

Schematic structures of the reassortant CMV RNA genomes of the two parent CMV strains, $\mathrm{CMV}(\mathrm{Y})$ and $\mathrm{CMV}(\mathrm{H})$, are shown in Figure S1. When fully-expanded leaves of three independent A. thaliana ecotype Col-0 plant were inoculated with one of the reassortant CMVs [CMV(HHY), $\mathrm{CMV}(\mathrm{HYY}), \mathrm{CMV}(\mathrm{YHH}), \mathrm{CMV}(\mathrm{YYH}), \mathrm{CMV}(\mathrm{YHY})$ or CMV(HYH); and CMV(Y) or CMV(H) strain as a control], a cell death developed at $5 \mathrm{dpi}$ in those inoculated with three of the reassortant CMVs containing CMV(H) RNA1: CMV(HHY), CMV(HYY), or CMV(HYH). However, cell death did not occur in Col-0 leaves inoculated with other reassortant CMV, CMV(Y), or CMV(H) (Figure 1A and Figure S2). At 5 dpi, cell death (which affected a much larger area in comparison with HR cell death) developed in Col-0 leaves inoculated with CMV(HHY), CMV(HYY), or CMV(HYH); whereas HR cell death developed in CMV(Y)-inoculated leaves of RCY1-transformed Col-0 (Col::RCY1) at 3 dpi (Figure 1A and Figure S2A,B). These results suggest that CMV(H) RNA1 might be associated with cell death development in reassortant CMV-inoculated leaves through its interaction with CMV(Y) RNA2 
or CMV(Y) RNA3 and a characteristic of this cell death is to spread to a broader area around the virus primary infection site than occurs with HR cell death.

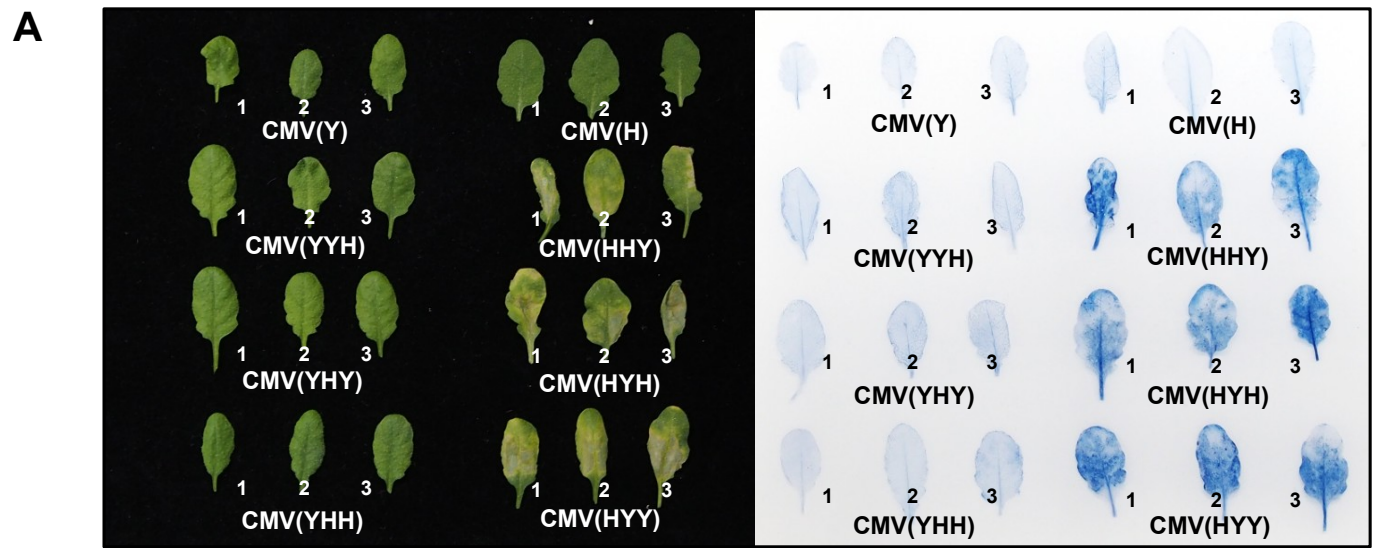

B

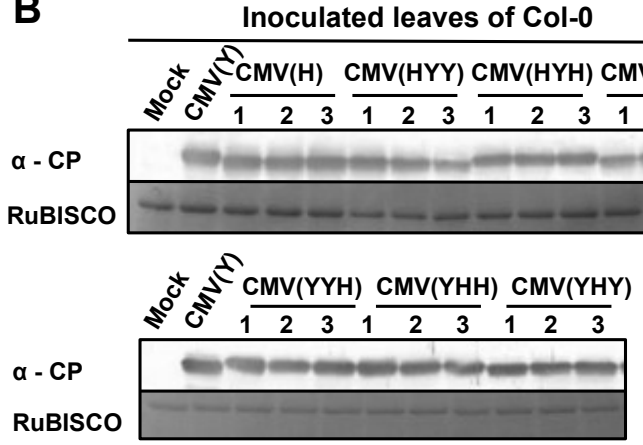

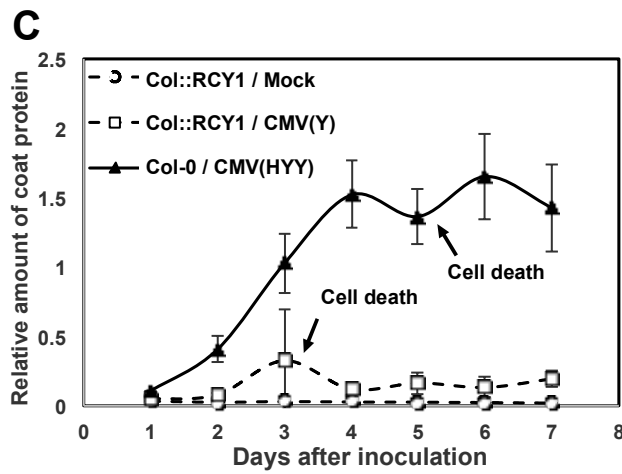

Figure 1. Response of virus-inoculated leaves of Arabidopsis thaliana ecotype Col-0 to CMV(H), CMV(Y), or a series of reassortant CMVs, and virus multiplication in the inoculated leaves. (A) Development of cell death in leaves with a series of reassortant CMVs, or with $\mathrm{CMV}(\mathrm{H})$ or $\mathrm{CMV}(\mathrm{Y})$ as a control. Representative virus-inoculated Col-0 of three independent plants (plant numbers 1, 2, and 3) under bright field (left panel) and stained with trypan blue (right panel). (B) CMV CP detected immunologically by western blotting at $7 \mathrm{dpi}$ in the leaves of plants inoculated with one of a series of reassortant CMVs. $\mathrm{CMV}(\mathrm{Y})$-inoculated Col-0 leaves and mock-inoculated Col-0 leaves were used as positive and negative control. RuBISCO protein is shown as an internal reference for protein quantity. (C) Time course of virus multiplication in Col-0 leaves inoculated with CMV(HYY) carrying CMV(H) RNA1 [Col-0/CMV(HYY)], CMV(Y)-inoculated Col::RCY1 leaves [Col::RCY1/CMV(Y)], and mock-inoculated Col::RCY1 leaves [Col::RCY1/Mock]. CMV CP quantities were measured using ELISA (mean values of relative amount of CP of three independent biological samples with standard error bars).

The intensities of CMV CP bands detected by western blot analysis in CMV(HYY)-, CMV(HHY)-, or CMV (HYH)-inoculated leaves of Col-0 exhibiting cell death were comparable to those in CMV(Y)-, $\mathrm{CMV}(\mathrm{H})$-, or other reassortant CMV-inoculated Col-0 leaves showing no cell death at 5 dpi (Figure 1B). The accumulated level of CP in CMV(HYY)-inoculated leaves was also quantitatively similar to that in $\mathrm{CMV}(\mathrm{Y})$-inoculated Col-0 showing no cell death, but significantly higher than in CMV(Y)-inoculated Col::RCY1 leaves showing HR cell death (Figure 1C and Figure S3). Furthermore, comparison of the intensity of the norther blot analysis bands of CMV RNA1, RNA2, and RNA3 among the leaves inoculated with eight CMVs [CMV(H), CMV(Y), or one of six reassortant CMVs] suggests that there is no significant correlation between the induction of cell death and the accumulated level of CMV RNAs or the ratio of CMV RNA1, RNA2, and RNA3 (Figure 2). These results indicate that the cell death developing on the leaves inoculated with reassortant CMV carrying CMV(H) RNA1, 
seems to not suppress virus replication but instead allows it to multiply at the same level as with a susceptible interaction.

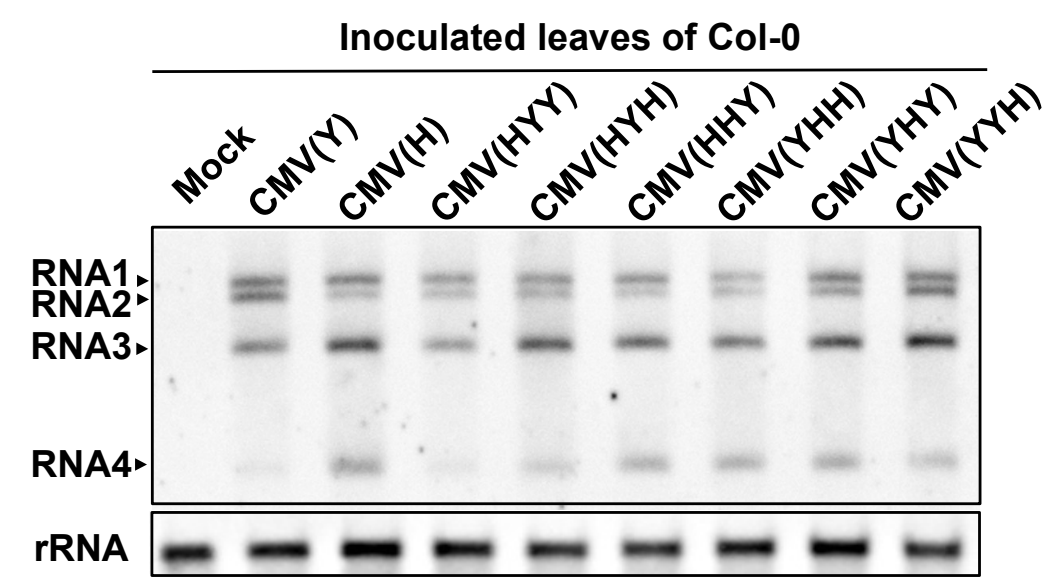

Figure 2. Detection of CMV RNA in virus-inoculated leaves of Arabidopsis thaliana ecotype Col-0. CMV RNA1, 2, 3, and 4 were detected by northern blot hybridization analysis of total RNA extracted from virus-inoculated leaves of Col-0 inoculated with $\mathrm{CMV}(\mathrm{Y}), \mathrm{CMV}(\mathrm{H})$ and a series of reassortant $\mathrm{CMVs}$ (as indicated) at $5 \mathrm{dpi}$. Mock-inoculated Col-0 leaves were used as a control. Total RNA was extracted from three independent samples. The position of CMV RNA is indicated at left: RNA 1, 2, and 3 represent genomic RNAs; RNA4 is subgenomic. rRNA is the loading control.

To investigate whether or not the cell death developing on the leaves inoculated with CMV(HYY) carrying CMV(H) RNA1 affects virus systemic spread to noninoculated upper leaves, $\mathrm{CP}$ in noninoculated upper leaves of CMV(HYY)-infected Col-0, CMV(Y)-infected Col::RCY1, or mock-inoculated Col-0 was detected by western blot analysis (Figure 3A). CP only accumulated in noninoculated upper leaves of CMV(HYY)-inoculated plants showing systemic stunting and weak yellowing symptoms, but not in upper leaves of CMV(Y)-infected Col::RCY1 or mock-inoculated Col-0. Moreover, systemic cell death was not observed in CMV(HYY)-inoculated plants or CMV(Y)-infected Col::RCY1 or mock-inoculated Col-0 (Figure 3B). Thus, the cell death developing on the leaves inoculated with reassortant CMV carrying $\mathrm{CMV}(\mathrm{H}) \mathrm{RNA} 1$ seems to not contribute to the resistance to $\mathrm{CMV}$, and therefore differs from HR cell death. 

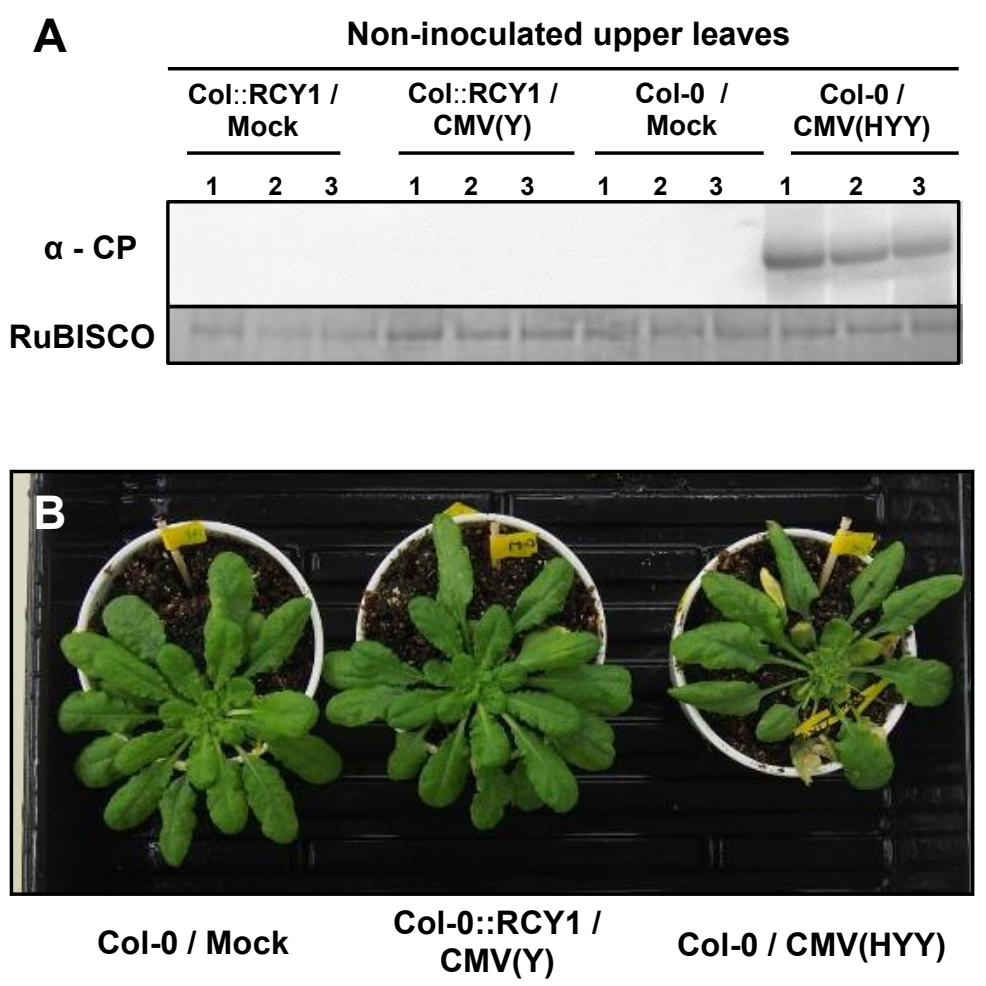

Figure 3. Detection of CMV CP in noninoculated upper Arabidopsis thaliana ecotype Col-0 leaves and systemic symptom development. (A) CMV CP detected at $7 \mathrm{dpi}$, by western blot analysis, in noninoculated upper leaves of CMV(HYY)-infected or mock-inoculated Col-0 [Col-0/CMV(HYY) and Col-0/Mock] and CMV(Y)-inoculated or mock-inoculated Col::RCY1 [Col::RCY1/CMV(Y) and Col::RCY1/Mock]. RuBISCO protein is an internal reference for protein quantity. Each experiment was conducted using three independent biological replicates (plant numbers 1, 2, and 3). (B) Symptom appearance observed at $14 \mathrm{dpi}$ on CMV(HYY)-inoculated Col-0 [Col-0/CMV(HYY)], CMV(Y)-inoculated Col::RCY1 [Col::RCY1/CMV(Y)], or mock-inoculated Col-0 [Col-0/Mock] (control). Virus-inoculated leaves have been removed because they were already dead at this stage. Representative plants were photographed.

\subsection{Response of A. thaliana Ecotypes to $C M V(H Y Y)$}

To determine whether the cell death induced in CMV(HYY)-inoculated leaves of $A$. thaliana ecotype Col-0 is a general response in $A$. thaliana ecotypes, 94 ecotypes of $A$. thaliana were inoculated with CMV(HYY). Cell death developed in virus-inoculated leaves in 92 out of 94 ecotypes from 5 to $9 \mathrm{dpi}$, but not in the ecotypes Mt-0 and Stw- 0 at $14 \mathrm{dpi}$ (Figure 4A,B, and Table S1). According to our repetitive experiments, we could not detect necrosis induction in $\mathrm{CMV}(\mathrm{HYY})$-inoculated leaves of Stw- 0 and Mt-0, even if we cultivated them more than one month after inoculation (data not shown). CMV CP was detected in CMV(HYY)-inoculated Mt- 0 and Stw- 0 at similar levels to Col- 0 , but not in the virus-inoculated leaves of the other 92 ecotypes (Figure 4C). Cell death was not observed on the upper leaves of any of the 94 ecotypes systemically infected with CMV(HYY) (data not shown). Thus, A. thaliana ecotypes appear to generally develop cell death in response to CMV(HYY). 
A

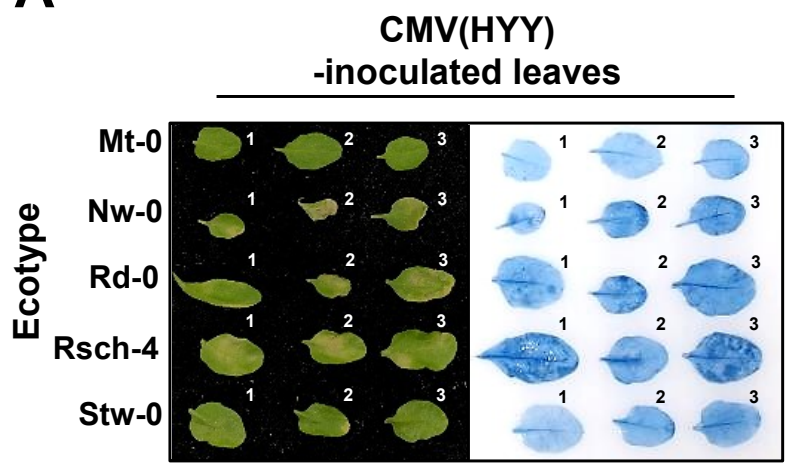

B

2 ecotypes

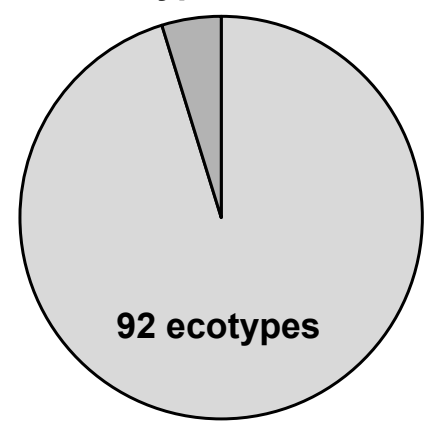

Cell death (+) $\quad \square$ Cell death (-)

C

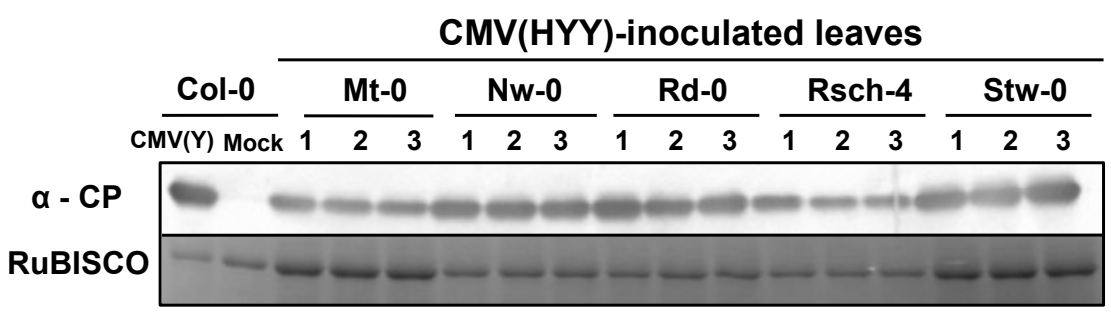

Figure 4. Survey of the response to CMV(HYY)-inoculation on the leaves of 94 ecotypes of Arabidopsis thaliana. (A) Representative photograph of the responses: CMV(HYY)-inoculated leaves of five ecotypes randomly selected at $14 \mathrm{dpi}$. Virus-inoculated leaves under bright field (left panel) and stained with trypan blue (right panel). (B) Pie chart summary of CMV(HYY)-inoculated leaves of the 94 ecotypes. (C) CMV CP detected immunologically by western blot analysis in virus-inoculated leaves of three independent biological replicates (numbers 1, 2, and 3) of five selected ecotypes at 7 dpi. RuBISCO protein is an internal reference for protein quantity.

\subsection{Comparison of Global Gene Expression Pattern between Two Types of Cell Death in Arabidopsis Leaves}

To further characterize cell death in CMV-inoculated Col-0 leaves, global gene expression patterns were compared by RNA-Seq analysis between CMV(HYY)-inoculated Col-0 leaves showing cell death and CMV(Y)-inoculated Col::RCY1 leaves showing characteristic HR cell death. Changes in transcript abundances in CMV(HYY)-inoculated Col-0 leaves showing cell death and CMV(Y)-inoculated Col::RCY1 showing HR cell death were compared against mock treatment controls for 5906 genes with sufficient read counts for statistical analyses (adjusted $p$-value $<0.05$ ). Genes were considered DEGs (differentially expressed genes) during the analysis of DESeq2 (Tables S5-S10) for a $>4$-fold increase in expression or a $<0.25$-fold decrease in expression at an adjusted $p$-value of $<0.05$. As shown in Figure 5, a total of 202 genes showed a $>4$-fold increase in transcript abundance. Of these, 35 transcripts (Class II) showed significant increase in common with CMV(HYY)-induced cell death and CMV(Y)-induced HR cell death; while 149 transcripts (Class I) showed a significant unique increase in $\mathrm{CMV}(\mathrm{Y})$-induced HR; and 18 transcripts (Class III) showed a similar such increase in CMV(HYY)-induced cell death (Figure 5; Tables S5-S7). Simultaneously, 62 genes showed a significant $<0.25$-fold decrease in transcript abundance (Figure 5). Of these, seven (Class V) showed a common significant decrease; 43 (Class IV) specifically decreased in CMV(Y)-induced HR; and 12 (Class VI) showed a decrease in CMV(HYY)-induced cell death (Figure 5; Tables S8-S10). These results indicate that global gene expression patterns in CMV(HYY)-inoculated Col-0 leaves developing cell death is different from that in characteristic HR cell death coupled to RCY1-conferred CMV(Y) resistance. 

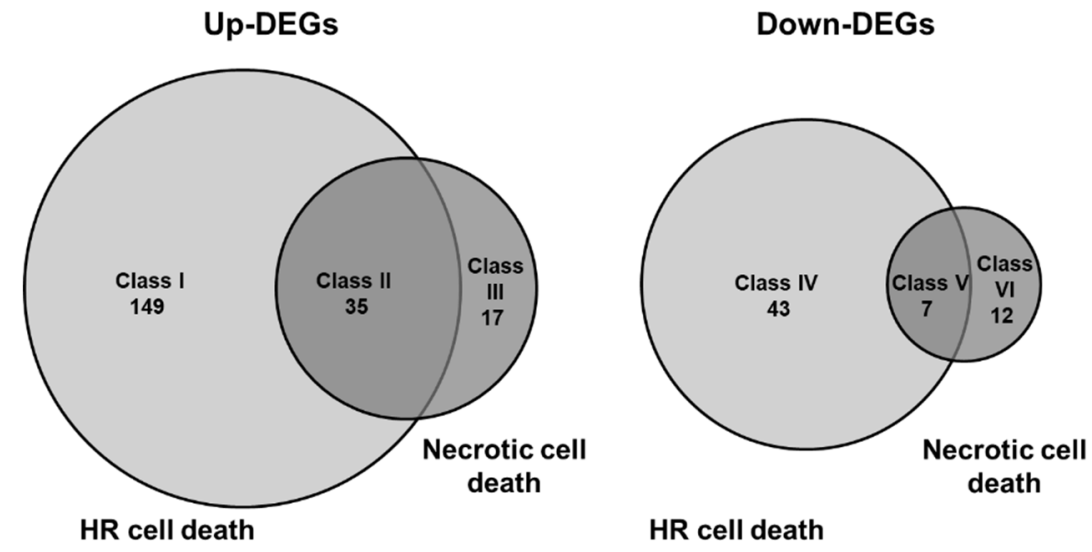

Figure 5. Venn diagram of the number of genes with increased or decreased transcript abundance in CMV(HYY)-inoculated Arabidopsis thaliana Col-0 leaves showing necrotic cell death and CMV(Y)-inoculated Col::RCY1 leaves showing HR cell death. The number of genes detected by RNA-Seq analysis with more than 4-fold increased expression and adjusted $p<0.05$ in CMV(HYY)-inoculated Col-0 leaves and CMV(Y)-inoculated Col::RCY1 leaves are shown at left (Up-DEGs). Those with less than 0.25 -fold decreased expression $(p<0.05)$ are shown at right (Down-DEGs). The number of genes with increased and decreased expression in leaves showing HR cell death are shown in the light gray circles; and those showing necrotic cell death in the dark gray circles.

The number of genes for which transcript expression increased $>4$-fold or decreased $<0.25$-fold in CMV(HYY)-inoculated Col-0 leaves showing cell death was much lower than that in CMV(Y)-inoculated Col::RCY1 leaves showing HR cell death (Figure 5). Furthermore, the genes (Class I genes) with increased transcript abundance in CMV(Y)-inoculated Col::RCY1 leaves encoded several defense-related proteins: chitinase, pathogenesis-related (PR) proteins, and WRKY transcription factors; several leucine-rich repeat kinases and receptor-like proteins; calcium-binding EF-hand family proteins; and glutathione $S$-transferases (Table S5). Gene ontology (GO) enrichment analysis suggested that the top three GO enrichment term in the biology processes for the identified DEGs with increased expression specific to HR cell death were enriched in "systemic acquired resistance", "salicylic acid (SA) metabolic process", and "SA biosynthetic process" (Figure S8, Table S11). Transcripts encoded by overlapping sets of genes (Class II genes) were enriched in GO terms "systemic acquired resistance", "SA biosynthetic process", and "cell death" and could therefore be associated generally with the induction of cell death (Figure S9, Table S12). In contrast, transcripts of Class III genes specific to cell death in CMV(HYY)-inoculated leaves were enriched in GO terms such as "jasmonic acid (JA)-mediated signaling pathway", "cellular response to JA stimulus", and "response to JA" (Figure S10, Table S13), perhaps indicating a form of necrotic cell death that does not contribute to the resistance to CMV.

\subsection{Analysis of the Viral Sequence in CMV RNA1 Inducing Necrotic Cell Death in Virus-Inoculated Leaves}

Induction of necrotic cell death in CMV(HYY)-inoculated Col-0 leaves but not in $\mathrm{CMV}(\mathrm{Y})$-inoculated Col-0 leaves suggested that $\mathrm{CMV}(\mathrm{H}) \mathrm{RNA1}$ is responsible for inducing necrotic cell death with co-infection of CMV(Y) RNA2 and RNA3 in virus-inoculated leaves (Figure 1). There are 26 non-synonymous amino acid substitutions in 1a protein encoded on RNA1 of CMV(H) and CMV(Y) (Figure 6). To identify the region of 1 a protein encoded by $\mathrm{CMV}(\mathrm{H}) \mathrm{RNA} 1$ responsible for inducing necrotic cell death in virus-inoculated Col-0 leaves, a series of chimeric cDNAs between CMV(Y) and $\mathrm{CMV}(\mathrm{H})$ RNA1 were generated and cloned under the control of the T7 promoter (Figures 7A, 8A and 9A). Each infectious RNA1 was transcribed in vitro from each chimeric cDNA vector, combined with infectious RNA 2 and RNA3 from $\mathrm{CMV}(\mathrm{Y})$, and used as inoculum.

When fully expanded leaves of Col-0 were inoculated with CMV(Y-H/683) and CMV(H-Y/683), which contain chimeric regions from nucleotide positions 1144 to the $3^{\prime}$-end of the 1 a protein-coding 
sequence (due to reciprocal RNA1 cDNA fragment exchanges between RNA1 cDNA vectors $\mathrm{Y}$ and $\mathrm{H}$; Figure 7A), necrotic cell death developed in fully expanded Col-0 leaves inoculated with CMV(H-Y/683) containing infectious RNA1 transcribed from chimeric RNA1 cDNA vector H-Y/683, as well as the leaves inoculated with CMV(HYY) (Figure 7B). However, cell death did not occur in leaves inoculated with either $\mathrm{CMV}(\mathrm{Y}-\mathrm{H} / 683$ ) or $\mathrm{CMV}(\mathrm{Y})$ (Figure 7B). Systemic cell death was not observed in any upper leaves of either $\mathrm{CMV}(\mathrm{H}-\mathrm{Y} / 683)$ - or $\mathrm{CMV}(\mathrm{Y}-\mathrm{H} / 683)$-inoculated plants (data not shown), although the CMV CP was detected in the upper leaves in similar amounts in CMV(H-Y/683) and CMV $(\mathrm{Y}-\mathrm{H} / 683)$ (Figure S4). These results suggest that the region encoding 1a protein of $\mathrm{CMV}(\mathrm{H})$, which does not contain the helicase (HEL) domain, is necessary to develop necrotic cell death.

When fully expanded leaves of Col-0 were inoculated with CMV(Y-H/343) and CMV(Y-H/344 682), which contain chimeric regions from nucleotide positions 1127 to 2143 in the 1 a protein-coding sequence due to reciprocal RNA1 cDNA fragment exchanges between RNA1 cDNA vectors Y and H-Y/683 (Figure 8A), necrotic cell death developed on the leaves inoculated with $\mathrm{CMV}(\mathrm{Y}-\mathrm{H} / 343)$, but not on those inoculated with $\mathrm{CMV}(\mathrm{Y}-\mathrm{H} / 344 \sim 682)$ (Figure 8B). Systemic cell death was not observed in the upper leaves of CMV(Y-H/344 682)- or CMV(Y-H/343)-inoculated plants (data not shown), although the CMV CP was detected at similar levels both in virus-inoculated leaves and the noninoculated upper leaves of these plants compared with $\mathrm{CMV}(\mathrm{Y})$ - and $\mathrm{CMV}(\mathrm{HYY})$-inoculated plants as controls (Figure S5). Thus, the determinant for inducing necrotic cell death seems to be located in the $5^{\prime}$ region of RNA1, which corresponds to nucleotide positions 1-1126 in the 1a protein-coding region and includes the methyltransferase (MET) domain.

A total of 11 amino acid substitutions remain in 1a protein encoding the region between nucleotide positions 1 and 1126 of RNA1 of $\mathrm{CMV}(\mathrm{H})$ and $\mathrm{CMV}(\mathrm{Y})$ (Figure 6). Next, to further delimit the determinant that induces necrotic cell death, fully expanded leaves of Col-0 were inoculated with CMV(Y-H/71), CMV(Y-H/72 343), CMV(Y-H/290), CMV(Y-H/72 290), CMV(Y-H/71 + 291 343), or $\mathrm{CMV}(\mathrm{Y}-\mathrm{H} / 291 \sim 343)$, which carries chimeric regions (Figure 9A) from nucleotide positions 1 to 310, 311 to 967, and 968 to 1126 in their 1a protein coding regions, respectively (Figures 6 and 9A). Necrotic cell death developed on Col-0 leaves inoculated with CMV(Y-H/71), CMV(Y-H/72 343), CMV(Y-H/290), CMV(Y-H/71 + 291 343), or CMV(Y-H/291 343), but not on those inoculated with CMV(Y-H/72 290) (Figure 9B). Systemic cell death was not observed in upper leaves of plants systemically infected with CMV(Y-H/71), CMV(Y-H/72 343), CMV(Y-H/290), CMV(Y-H/72 290), CMV(Y-H/71 + 291 343), or CMV(Y-H/291 343) (data not shown), although the CMV CP was detected in virus-inoculated leaves and noninoculated upper leaves at similar levels (Figure S6). Thus, the development of the necrotic cell death seems to be determined by two independent regions of the 1 a protein-coding region from nucleotide positions 1-310 or 968-1126, which do not include the MET domain (Figures 6 and 9A). These two distinct 1 a protein-coding regions, which equally determine the induction of the necrotic cell death, contained three amino acid differences between $\mathrm{CMV}(\mathrm{Y})$ and $\mathrm{CMV}(\mathrm{H})$ (Figures 6 and 9A), respectively. 


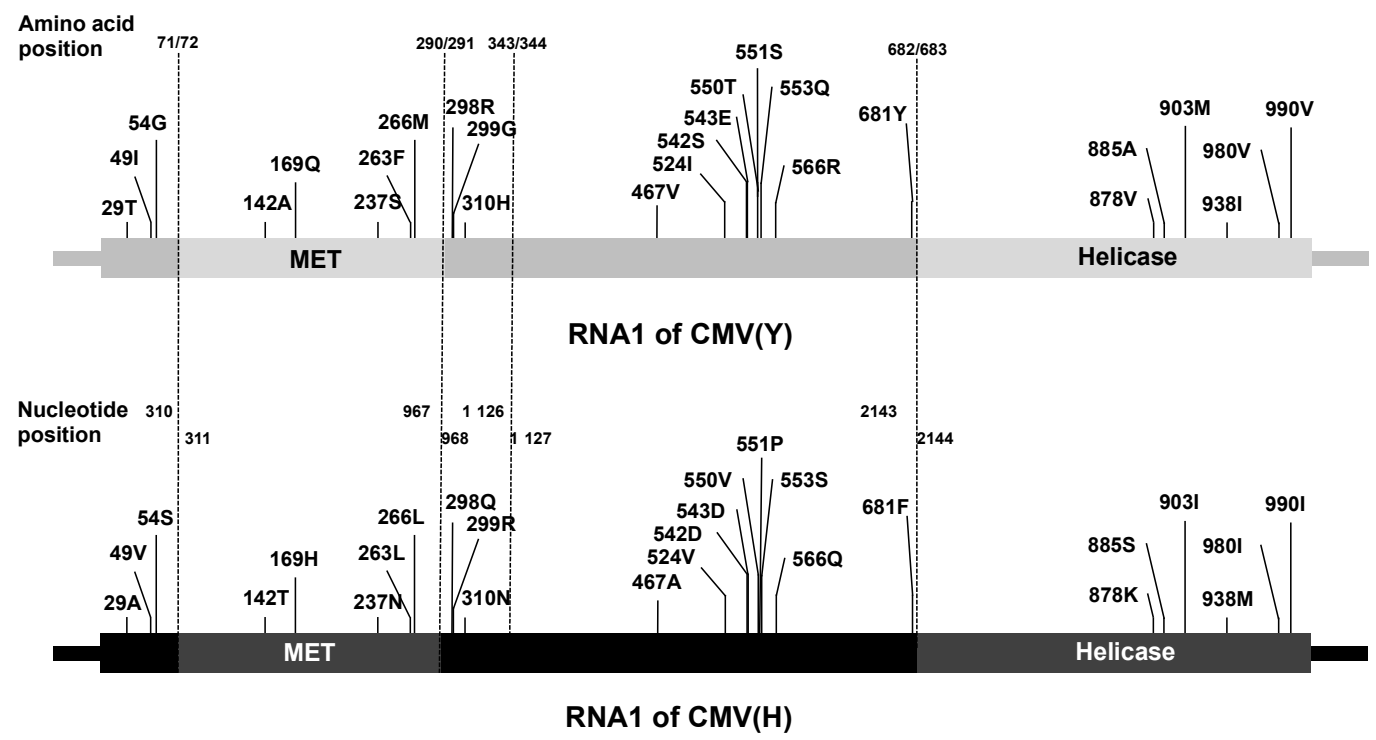

Figure 6. Schematic diagram of the CMV RNA1 encoding the 1a protein, which contains a methyltransferase (MET) and a helicase (HEL) domain. The 1a protein-coding region and corresponding 1a protein are shown as rectangles. Amino acids that differ between the 1a proteins encoded by the CMV(H) RNA1 (lower panel) and the CMV(Y) RNA1 (upper panel) and the positions of these amino acids in the 1a protein are described above each rectangle. The dotted lines connecting the two chimeric constructs indicate the amino acid and nucleotide positions of junction sites. The adjacent sequence numbers of each of these junctions are indicated above the CMV(Y) RNA1 (upper) schematic for amino acids; and above the CMV(H) RNA1 (lower) schematic for the corresponding nucleotides.

A

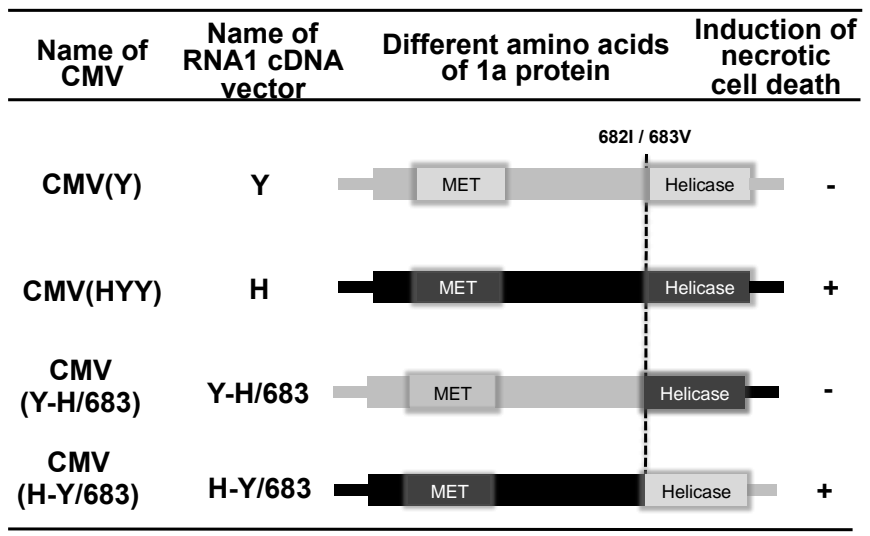

$B$

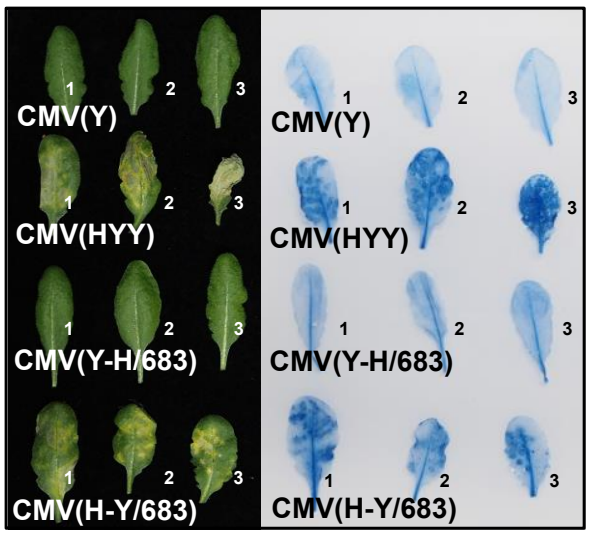

Figure 7. Induction of necrotic cell death in Arabidopsis thaliana ecotype Col-0 leaves inoculated with reassortant CMVs, $\mathrm{CMV}(\mathrm{H}-\mathrm{Y} / 683)$ and $\mathrm{CMV}(\mathrm{Y}-\mathrm{H} / 683)$, which carry chimeric 1a protein of $\mathrm{CMV}(\mathrm{Y})$ and $\mathrm{CMV}(\mathrm{H}), \mathrm{CMV}(\mathrm{Y})$, and $\mathrm{CMV}(\mathrm{HYY})$. (A) Schematic diagram of the CMV RNA1 encoding the 1a protein. The 1a protein-coding region (and its corresponding 1a protein) is presented as rectangles in black for $\mathrm{CMV}(\mathrm{H})$ and in gray for $\mathrm{CMV}(\mathrm{Y})$. The dotted line indicates the junction site at amino acid position 682/683. MET, 1a protein methyltransferase domain; HEL, helicase domain. The presence (+) or absence (-) of necrotic cell death induction in virus-inoculated leaves is shown in the column on the right. (B) Responses of CMV-inoculated leaves for three independent biological replicates (plants number 1, 2, and 3). Virus-inoculated leaves to the left are under bright field and those to the right are stained with trypan blue. 
A

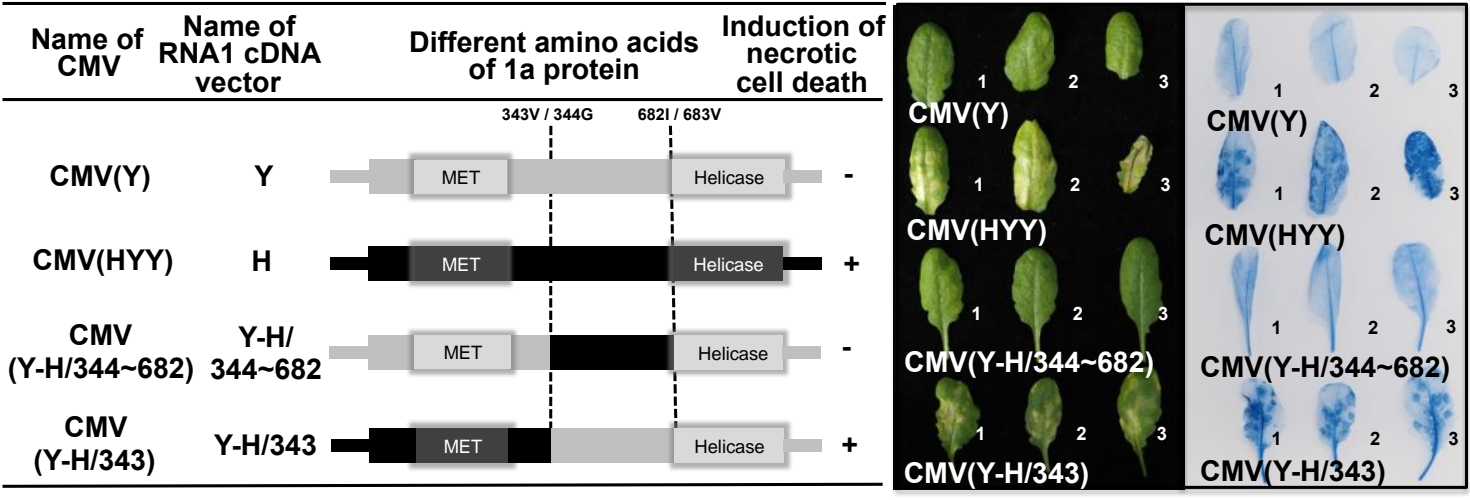

Figure 8. Induction of necrotic cell death in Arabidopsis thaliana ecotype Col-0 leaves inoculated with reassortant $\mathrm{CMVs}$, $\mathrm{CMV}(\mathrm{Y}-\mathrm{H} / 343)$, and $\mathrm{CMV}(\mathrm{Y}-\mathrm{H} / 344 \sim 682)$ which carry chimeric 1a protein of $\mathrm{CMV}(\mathrm{Y})$ and $\mathrm{CMV}(\mathrm{H})$, and $\mathrm{CMV}(\mathrm{Y})$ and $\mathrm{CMV}(\mathrm{HYY})$. (A) Schematic diagram of the CMV RNA1 encoding the 1a protein (representation as in Figure 7: see legend for details). The junction sites in chimeric 1a proteins at amino acid positions 343/344 and 682/683 are indicated by dotted lines. (B) Responses of CMV-inoculated leaves (for details, see legend to Figure 7).

A

B

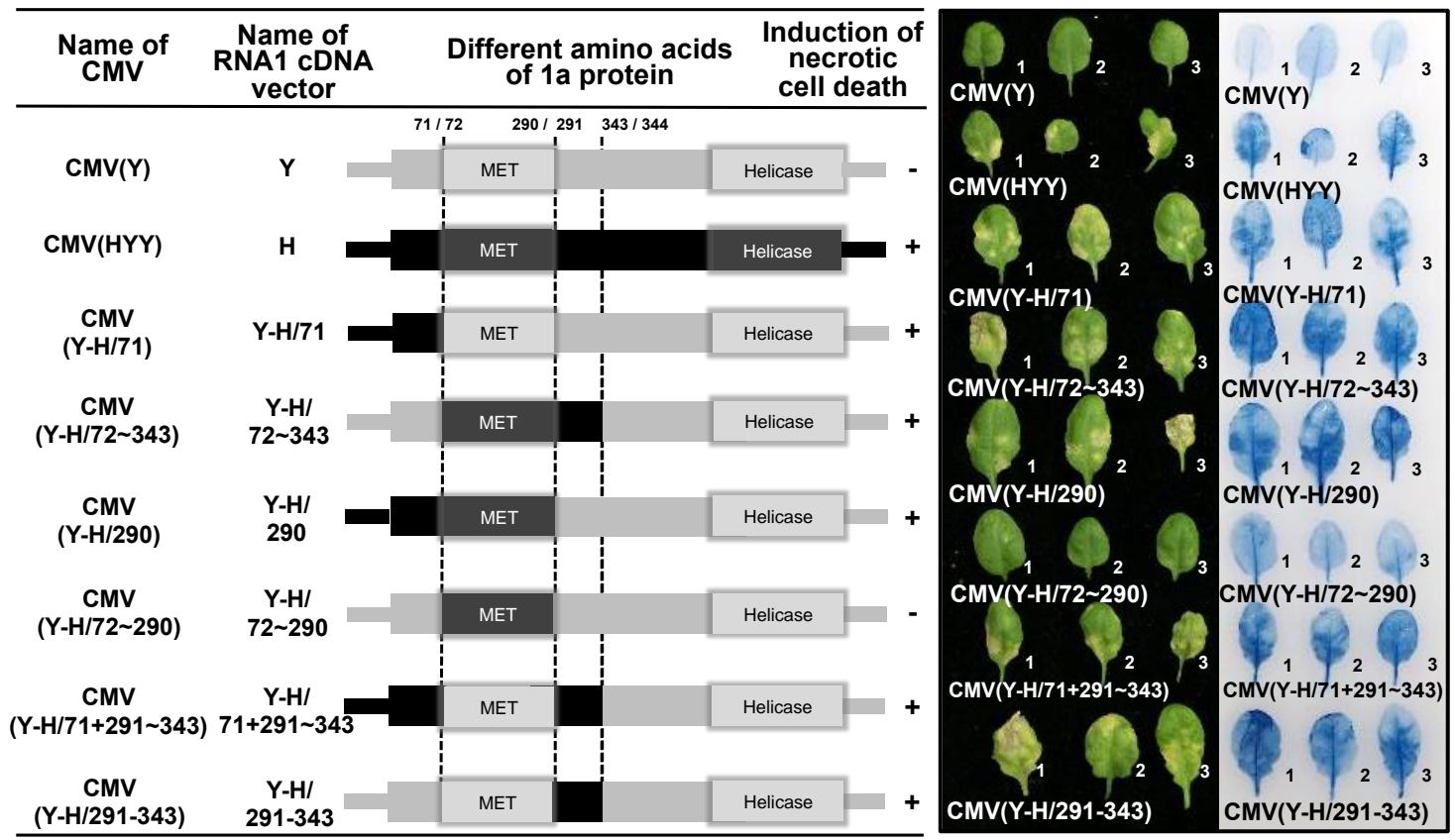

Figure 9. Induction of necrotic cell death in Arabidopsis thaliana ecotype Col-0 leaves inoculated with reassortant CMVs, CMV(Y-H/71), CMV(Y-H/72 343), CMV(Y-H/290), CMV(Y-H/72 290), CMV(Y-H/71 + 291 343), and CMV(Y-H/291 343), which carry chimeric 1a protein of $\mathrm{CMV}(\mathrm{Y})$ and $\mathrm{CMV}(\mathrm{H})$, and $\mathrm{CMV}(\mathrm{Y})$ and $\mathrm{CMV}(\mathrm{HYY})$. (A) Schematic diagram of the CMV RNA1 encoding the 1a protein (representation as in Figure 7: see legend for details). Dotted lines indicate the chimera junction sites at amino acid positions 71/72, 290/291, and 343/344. (B) Responses of CMV-inoculated leaves (for details, see legend to Figure 7).

3.5. Analysis of Single Amino Acid Substitutions in the CMV 1a Protein for Induction of Necrotic Cell Death in Virus-Inoculated Leaves

To determine which amino acid in each region of the 1a protein induces necrotic cell death, nucleotide substitutions resulting in single amino acid substitutions were generated in each $\mathrm{CMV}(\mathrm{Y})$ 1a protein-coding region (Figure 10A). Necrotic cell death was induced in Col-0 leaves inoculated with 
CMV(T29A), CMV(I49V), CMV(G54S), CMV(R298Q), CMV(G299R), and CMV(H310N), respectively (Figure 10B). Systemic cell death was not observed in upper leaves of plants systemically infected with CMV(T29A), CMV(I49V), CMV(G54S), CMV(R298Q), CMV(G299R), and CMV(H310N) (data not shown), although the CMV CP was detected in virus-inoculated leaves and noninoculated upper leaves at similar levels (Figure S7). These results indicate that amino acid residues 29, 49, 54, 298, 299, and 310, which are located around the MET domain in the 1a protein encoded on CMV(Y) RNA1, independently determine the induction of necrotic cell death upon co-infection of Col-0 leaves with CMV(Y) RNA2 and RNA3.

A

B

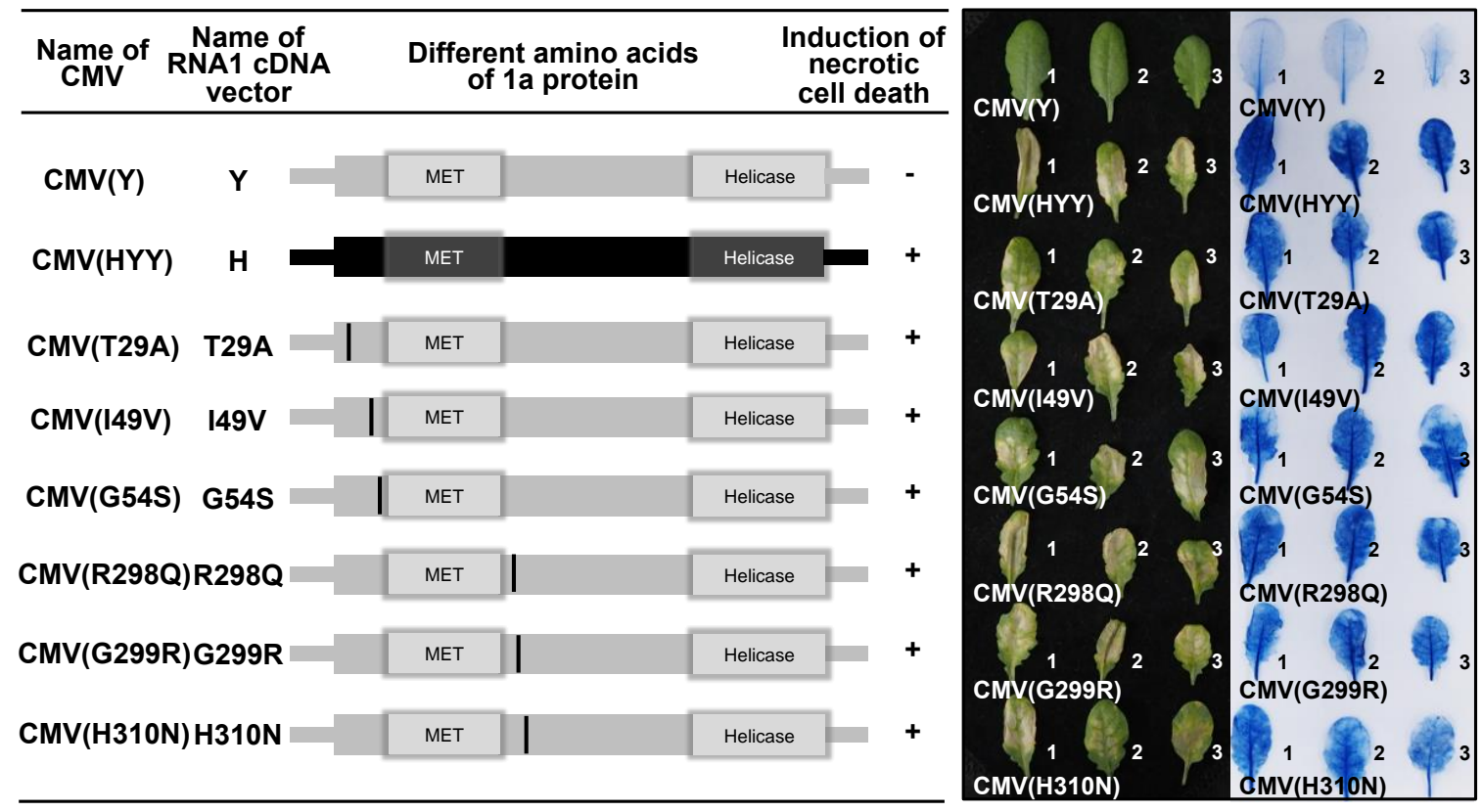

Figure 10. Induction of necrotic cell death in Arabidopsis thaliana ecotype Col-0 leaves inoculated with CMVs carrying single amino acid substitutions in the 1a protein of CMV(Y). (A) Schematic diagram of the CMV RNA1 encoding the 1a protein. The 1a protein-coding region and corresponding 1a protein are shown as rectangles. Deduced single amino acid substitutions and their positions in the 1a protein are shown as a black bar (representation as in Figure 7: see legend for details). (B) Responses of CMV-inoculated leaves (for details, see legend to Figure 7).

\section{Discussion}

The response of $A$. thaliana ecotype Col-0 to a series of reassortant viruses with different chimeric composition of two CMV strains of differing virulence, $\mathrm{CMV}(\mathrm{H})$ and $\mathrm{CMV}(\mathrm{Y})$, was that necrotic cell death developed only in virus-inoculated leaves of Col-0 infected with reassortant CMVs carrying $\mathrm{CMV}(\mathrm{H})$ RNA1; for example, CMV(HYY) as shown in Figure 1. The amount of CMV CP accumulated in CMV(HYY)-inoculated Col-0 leaves was similar to that in CMV(Y)-inoculated Col-0 leaves showing necrotic cell death was similar to that in CMV(Y)-inoculated Col-0 leaves, which are susceptible to CMV(Y) but show no cell death (Figure 1 and Figure S3). Furthermore, both CMV(HYY) and CMV(Y) spread systemically in Col-0 plants (Figure 3). Therefore, the necrotic cell death developing on leaves inoculated with reassortant CMVs carrying CMV(H) RNA1 does not confer resistance to CMV, which is different from what happens with HR cell death.

When assessing host responses to reassortant CMVs, it was first considered that necrotic cell death might be an artifact caused by a heterogenous interaction between the $\mathrm{CMV}(\mathrm{H})$ 1a protein and other proteins encoded on CMV(Y) RNA2 and CMV (Y) RNA3, because CMV(H) itself did not induce necrotic cell death in virus-inoculated Col-0 leaves (Figure 1A). However, the results from 
single amino acid substitutions in the $\mathrm{CMV}(\mathrm{Y})$ 1a protein, were found to determine the occurrence of necrotic cell death, indicating that the mechanism of this necrotic cell death is likely to be more complex than that considered initially. The development of necrotic cell death in virus-inoculated leaves of Col-0 was induced by co-infection of CMV(Y) RNA2 and CMV(Y) RNA3 with a CMV(Y) RNA1 encoding a 1a protein carrying single amino acid substitutions around its MET domain, and this cell death did not affect virus multiplication. So far, it has been reported that a single amino acid substitution from $\mathrm{R}$ to $\mathrm{C}$ at amino acid position 461 of $\mathrm{CMV}$ 1a protein produces an HR-like necrotic phenotype in virus-inoculated leaves of Nicotiana tabacum, although the substitution does not affect virus multiplication [49]. Modeling of 1a protein has also demonstrated structural changes in the 1a protein caused by amino acid substitutions at position 461, which is relevant to an HR-like cell death phenotype [50]. Also, the HEL domain of the 1a protein of CMV isolate P0 [CMV(P0)] determines Cmr1-conferred resistance to CMV in pepper in a gene-for-gene manner [51]. These findings suggests that necrotic cell death (rather than being an artifact of a heterogenous interaction between the $\mathrm{CMV}(\mathrm{H})$ 1a protein and other proteins encoded on CMV(Y) RNA2 or CMV(Y) RNA3), may be induced by single amino acid mutation occurring naturally in $\mathrm{CMV}(\mathrm{Y})$ 1a protein during $\mathrm{CMV}(\mathrm{Y})$ multiplication in host cells.

In the experiments reported here, single amino acid substitutions at residues 29, 49, 54, 298, 299, or 310 in both the $\mathrm{N}$ - and C-terminal regions around the MET domain (amino acid 72 to 290) of the 1a protein (Figures 6 and 10) independently induced necrotic cell death in Col-0. Although mutation affecting the amino acid composition of the MET domain of 1a protein disrupt capping activities and virus replication [52], single amino acid substitutions at the $\mathrm{N}$ - and C-terminal regions around the MET domain did not affect virus multiplication and systemic spread in the host plants (Figure 10). It is also observed that the N-terminal region of the hinge located between the MET and HEL domains of the 1a protein appears to self-interact to form homodimers in a yeast two-hybrid system [23]. Thus, change in the degree of self-interaction or conformational modification of the homodimer structure of the $1 \mathrm{a}$ protein (which could resulted from single amino acid substitutions around its MET domain) might be associated with the induction of necrotic cell death in Col-0 leaves in response to CMV(Y) carrying single amino acid substitutions around the MET domain. Further study is necessary to elucidate the mechanisms by which necrotic cell death is induced by single amino acid substitutions around the MET domain. However, the results reported here suggest that necrotic cell death can occur without preventing virus infection and is not caused by the stress of virus infection but by specific interactions between the virus and its host plant.

In this study, the induction of necrotic cell death was confirmed among 92 ecotypes of $A$. thaliana in response to the infection of CMV(HYY), Stw-0 and Mt-0 abolished the induction of necrotic cell death. There may be underlying plant factors that confer the induction of necrotic cell death through its interaction with $\mathrm{CMV}(\mathrm{HYY})$, and they might be inactivated by mutation or disrupted by deletion in Stw-0 and Mt-0.

Recently, evidence is accumulating that systemic necrosis (which was considered as a symptom of compatible interaction between a virus and its host plant) may result from the induction of HR cell death with incomplete restriction of virus spread in host plants [53-59]. The lethal systemic cell death might have been caused by delayed HR cell death and escape of the virus to distant tissues, thereby leading to runaway cell death, because virus-induced lethal systemic necrosis is correlated with activation of defense-related signaling pathways (e.g., MAP-kinase cascade) which are associated with incompatible interactions between host plants carrying $R$ genes and avirulent strains of virus $[55,58]$. However, necrotic cell death in CMV(HYY)-inoculated Col-0 leaves did not cause lethal necrosis, even though the virus particles did systemically spread to noninoculated upper leaves of Col-0 plants (Figure 3B). This finding indicates that the necrotic cell death that developed in CMV(HYY)-inoculated Col-0 leaves might be a symptom of a compatible interaction between $A$. thaliana Col-0 and CMV, but not a resistance response to CMV or lethal systemic cell death caused by delayed HR cell death. Indeed, comparative RNA-Seq analysis of CMV(HYY)-inoculated Col-0 leaves and CMV(Y)-inoculated 
Col::RCY1 leaves, indicated that the numbers of up- or downregulated genes in $\mathrm{CMV}(\mathrm{Y})$-inoculated Col::RCY1 leaves showing HR cell death were much greater than those in CMV(HYY)-inoculated Col-0 leaves showing necrotic cell death.

Many genes whose expression was specifically upregulated in CMV(Y)-inoculated Col::RCY1 leaves encoded several SA signaling-dependent defense-related proteins, which might be associated with RCY1-conferred resistance to CMV through restricting virus spread around primary infection sites (Figure 5). However, a number of JA signaling-related genes (which seem not to affect virus multiplication) were upregulated in CMV(HYY)-inoculated Col-0 leaves (Figure 5). Therefore, the necrotic cell death observed in CMV(HYY)-inoculated Col-0 leaves might not be contributing to CMV resistance. Moreover, only a limited number of overlapping DEGs (which might be relevant to necrotic cell death and HR cell death) was identified (Figure 5). Further investigation of the function of gene products associated with the induction of cell death should reveal the significance of cell death in the interactions between viruses and host plants.

Cell death in virus-infected plants is a critical event for virus survival, because virus multiplication depends on host cell metabolism. However, the role of cell death in virus-host plant interactions remains poorly understood. The finding of necrotic cell death in $A$. thaliana, which is determined by CMV-encoded 1a protein but unrelated to CMV resistance and HR cell death (including lethal systemic cell death), presents a new pathosystem to investigate the role of necrotic cell death in virus-host plant interactions.

Supplementary Materials: Supplementary materials can be found at http://www.mdpi.com/1999-4915/12/1/91/s1.

Author Contributions: H.T. conceived the study; A.T., H.T., and S.A. conducted the experiments; A.T., S.M., and S.A. analyzed the data; A.T. and S.M. performed statistical tests; A.T., S.M., S.A., and H.T. interpreted the results. All authors approved the final version of the manuscript for publication.

Funding: This study was funded by grants for "Scientific Research on Innovative Areas" from the Ministry of Education, Culture, Science, Sports and Technology (MEXT), Japan (grant numbers 16H06429, 16K21723, and 16H06435), Grant-in-Aid for Scientific Research (B) (grant number 19H02953), Grant-in-Aid for Challenging Exploratory Research (grant number 19K22300), and the Japan Society for the Promotion of Science (JSPS) through the JSPS Core-to-Core Program (Advanced Research Networks) entitled "Establishment of international agricultural immunology research-core for a quantum improvement in food safety".

Acknowledgments: We thank the Human Genome Center at the University of Tokyo for allowing us to use their supercomputer.

Conflicts of Interest: The authors declare no conflict of interest.

Ethical Approval: No ethical approval was sought by the authors because this article does not include any studies involving animal or human participants.

\section{References}

1. Mur, L.A.; Kenton, P.; Lloyd, A.J.; Ougham, H.; Prats, E. The hypersensitive response; the centenary is upon us but how much do we know? J. Exp. Bot. 2007, 59, 501-520. [CrossRef]

2. Künstler, A.; Bacsó, R.; Gullner, G.; Hafez, Y.M.; Király, L. Staying alive-Is cell death dispensable for plant disease resistance during the hypersensitive response? Physiol. Mol. Plant Pathol. 2016, 93, 75-84. [CrossRef]

3. Hofius, D.; Schultz-Larsen, T.; Joensen, J.; Tsitsigiannis, D.I.; Petersen, N.H.; Mattsson, O.; Jørgensen, L.B.; Jones, J.D.; Mundy, J.; Petersen, M. Autophagic components contribute to hypersensitive cell death in Arabidopsis. Cell 2009, 137, 773-783. [CrossRef]

4. Hofius, D.; Tsitsigiannis, D.I.; Jones, J.D.; Mundy, J. Inducible cell death in plant immunity. Semin. Cancer Biol. 2007, 17, 166-187. [CrossRef] [PubMed]

5. Richael, C.; Gilchrist, D. The hypersensitive response: A case of hold or fold? Physiol. Mol. Plant Pathol. 1999, 55, 5-12. [CrossRef]

6. Hull, R. Plant Virology, 5th ed.; Academic Press: Salt Lake, UT, USA, 2013.

7. Goodman, R.N.; Novacky, A.J. The Hypersensitive Reaction in Plants to Pathogens: A Resistance Phenomenon; APS Press: St. Paul, MN, USA, 1994. 
8. Pontier, D.; Balagué, C.; Roby, D. The hypersensitive response. A programmed cell death associated with plant resistance. Comptes Rendus Acad. Sci. Ser. III Sci. 1998, 321, 721-734. [CrossRef]

9. Jones, J.D.; Dangl, J.L. The plant immune system. Nature 2006, 444, 323. [CrossRef] [PubMed]

10. Lam, E.; Kato, N.; Lawton, M. Programmed cell death, mitochondria and the plant hypersensitive response. Nature 2001, 411, 848. [CrossRef] [PubMed]

11. Fomicheva, A.S.; Tuzhikov, A.I.; Beloshistov, R.E.; Trusova, S.V.; Galiullina, R.A.; Mochalova, L.V.; Chichkova, N.V.; Vartapetian, A.B. Programmed cell death in plants. Biochemistry (Moscow) 2012, 77, 1452-1464. [CrossRef]

12. Morel, J.-B.; Dangl, J.L. The hypersensitive response and the induction of cell death in plants. Cell Death Differ. 1997, 4, 671. [CrossRef]

13. Greenberg, J.T.; Yao, N. The role and regulation of programmed cell death in plant-pathogen interactions. Cell. Microbiol. 2004, 6, 201-211. [CrossRef] [PubMed]

14. Heath, M.C. Hypersensitive response-related death. In Programmed Cell Death in Higher Plants; Springer: New York, NY, USA, 2000; pp. 77-90.

15. Canto, T.; Palukaitis, P. The hypersensitive response to cucumber mosaic virus in Chenopodium amaranticolor requires virus movement outside the initially infected cell. Virology 1999, 265, 74-82. [CrossRef] [PubMed]

16. Wright, K.M.; Duncan, G.H.; Pradel, K.S.; Carr, F.; Wood, S.; Oparka, K.J.; Santa Cruz, S. Analysis of the N gene hypersensitive response induced by a fluorescently tagged tobacco mosaic virus. Plant Physiol. 2000, 123, 1375-1386. [CrossRef] [PubMed]

17. Murphy, A.M.; Carr, J.P. Salicylic acid has cell-specific effects on tobacco mosaic virus replication and cell-to-cell movement. Plant Physiol. 2002, 128, 552-563. [CrossRef]

18. Lukan, T.; Baebler, Š.; Pompe-Novak, M.; Guček, K.; Zagorščak, M.; Coll, A.; Gruden, K. Cell death is not sufficient for the restriction of potato virus $\mathrm{Y}$ spread in hypersensitive response-conferred resistance in potato. Front. Plant Sci. 2018, 9, 168. [CrossRef]

19. Inaba, J.; Kim, B.M.; Shimura, H.; Masuta, C. Virus-induced necrosis is a consequence of direct protein-protein interaction between a viral RNA-silencing suppressor and a host catalase. Plant Physiol. 2011, 156, 2026-2036. [CrossRef]

20. Palukaitis, P.; García-Arenal, F. Cucumber Mosaic Virus; APS Press: St. Paul, MN, USA, 2018.

21. Rozanov, M.N.; Koonin, E.V.; Gorbalenya, A.E. Conservation of the putative methyltransferase domain: A hallmark of the 'Sindbis-like' supergroup of positive-strand RNA viruses. J. Gen. Virol. 1992, 73, 2129-2134. [CrossRef]

22. Habili, N.; Symons, R.H. Evolutionary relationship between luteoviruses and other RNA plant viruses based on sequence motifs in their putative RNA polymerases and nucleic acid helicases. Nucleic Acids Res. 1989, 17, 9543-9555. [CrossRef]

23. O'Reilly, E.K.; Wang, Z.; French, R.; Kao, C.C. Interactions between the structural domains of the RNA replication proteins of plant-infecting RNA viruses. J. Virol. 1998, 72, 7160-7169. [CrossRef]

24. Hayes, R.J.; Buck, K.W. Complete replication of a eukaryotic virus RNA in vitro by a purified RNA-dependent RNA polymerase. Cell 1990, 63, 363-368. [CrossRef]

25. Guo, H.S.; Ding, S.W. A viral protein inhibits the long range signaling activity of the gene silencing signal. EMBO J. 2002, 21, 398-407. [CrossRef] [PubMed]

26. Mlotshwa, S.; Voinnet, O.; Mette, M.F.; Matzke, M.; Vaucheret, H.; Ding, S.W.; Pruss, G.; Vance, V.B. RNA silencing and the mobile silencing signal. Plant Cell 2002, 14, S289-S301. [CrossRef] [PubMed]

27. Zhang, X.; Yuan, Y.-R.; Pei, Y.; Lin, S.-S.; Tuschl, T.; Patel, D.J.; Chua, N.-H. Cucumber mosaic virus-encoded 2b suppressor inhibits Arabidopsis Argonaute1 cleavage activity to counter plant defense. Genes Dev. 2006, 20, 3255-3268. [CrossRef] [PubMed]

28. González, I.; Martínez, L.; Rakitina, D.V.; Lewsey, M.G.; Atencio, F.A.; Llave, C.; Kalinina, N.O.; Carr, J.P.; Palukaitis, P.; Canto, T. Cucumber mosaic virus $2 \mathrm{~b}$ protein subcellular targets and interactions: Their significance to RNA silencing suppressor activity. Mol. Plant Microbe Interact. 2010, 23, 294-303. [CrossRef]

29. Schwinghamer, M.W.; Symons, R.H. Fractionation of cucumber mosaic virus RNA and its translation in a wheat embryo cell-free system. Virology 1975, 63, 252-262. [CrossRef]

30. Ding, B.; Li, Q.; Nguyen, L.; Palukaitis, P.; Lucas, W.J. Cucumber mosaic virus 3a protein potentiates cell-to-cell trafficking of CMV RNA in tobacco plants. Virology 1995, 207, 345-353. [CrossRef] 
31. Ding, S.W.; Anderson, B.J.; Haase, H.R.; Symons, R.H. New overlapping gene encoded by the cucumber mosaic virus genome. Virology 1994, 198, 593-601. [CrossRef]

32. Ando, S.; Miyashita, S.; Takahashi, H. Plant defense systems against cucumber mosaic virus: Lessons learned from CMV-Arabidopsis interactions. J. Gen. Plant Pathol. 2019, 85, 174-181. [CrossRef]

33. Sekine, K.; Kawakami, S.; Hase, S.; Kubota, M.; Ichinose, Y.; Shah, J.; Kang, H.G.; Klessig, D.F.; Takahashi, H. High level expression of a virus resistance gene, $R C Y 1$, confers extreme resistance to cucumber mosaic virus in Arabidopsis thaliana. Mol. Plant Microbe Interact. 2008, 21, 1398-1407. [CrossRef]

34. Takahashi, H.; Goto, N.; Ehara, Y. Hypersensitive response in cucumber mosaic virus-inoculated Arabidopsis thaliana. Plant J. 1994, 6, 369-377. [CrossRef]

35. Tomaru, K.; Hidaka, Z. Strains of cucumber mosaic virus isolated from tobacco plants. II. A mild strain. Bull. Hatano Tob. Exp. Stn. 1960, 46, 143-149. [CrossRef]

36. Suzuki, M.; Kuwata, S.; Kataoka, J.; Masuta, C.; Nitta, N.; Takanami, Y. Functional analysis of deletion mutants of cucumber mosaic virus RNA3 using an in vitro transcription system. Virology 1991, 183, 106-113. [CrossRef]

37. Sambrook, J.; Russel, D. Molecular Cloning: A Laboratory Manual, 3rd ed.; Cold Spring Harbor Laboratory Press: New York, NY, USA, 2001.

38. Takahashi, H.; Ehara, Y. Severe chlorotic spot symptoms in cucumber mosaic virus strain Y-infected tobaccos are induced by a combination of the virus coat protein gene and two host recessive genes. Mol. Plant Microbe Interact. 1993, 6, 182-189. [CrossRef] [PubMed]

39. Bradford, M.M. A rapid and sensitive method for the quantitation of microgram quantities of protein utilizing the principle of protein-dye binding. Anal. Biochem. 1976, 72, 248-254. [CrossRef]

40. Koenig, R. Indirect ELISA methods for the broad specificity detection of plant viruses. J. Gen. Virol. 1981, 55, 53-62. [CrossRef]

41. Bowling, S.A.; Guo, A.; Cao, H.; Gordon, A.S.; Klessig, D.F.; Dong, X. A mutation in Arabidopsis that leads to constitutive expression of systemic acquired resistance. Plant Cell 1994, 6, 1845-1857.

42. Bolger, A.M.; Lohse, M.; Usadel, B. Trimmomatic: A flexible trimmer for Illumina sequence data. Bioinformatics 2014, 30, 2114-2120. [CrossRef]

43. Dobin, A.; Davis, C.A.; Schlesinger, F.; Drenkow, J.; Zaleski, C.; Jha, S.; Batut, P.; Chaisson, M.; Gingeras, T.R. STAR: Ultrafast universal RNA-seq aligner. Bioinformatics 2013, 29, 15-21. [CrossRef]

44. Love, M.I.; Huber, W.; Anders, S. Moderated estimation of fold change and dispersion for RNA-seq data with DESeq2. Genome Biol. 2014, 15, 550. [CrossRef]

45. Benjamini, Y.; Hochberg, Y. Controlling the false discovery rate: A practical and powerful approach to multiple testing. J. R. Stat. Soc. Ser. B 1995, 57, 289-300. [CrossRef]

46. Chen, H.; Boutros, P.C. VennDiagram: A package for the generation of highly-customizable Venn and Euler diagrams in R. BMC Bioinform. 2011, 12, 35. [CrossRef] [PubMed]

47. Zhou, Y.; Zhou, B.; Pache, L.; Chang, M.; Khodabakhshi, A.H.; Tanaseichuk, O.; Benner, C.; Chanda, S.K. Metascape provides a biologist-oriented resource for the analysis of systems-level datasets. Nat. Commun. 2019, 10, 1523. [CrossRef] [PubMed]

48. Yu, G.; Wang, L.-G.; Han, Y.; He, Q.-Y. clusterProfiler: An R Package for Comparing Biological Themes Among Gene Clusters. OMICS J. Integr. Biol. 2012, 16, 284-287. [CrossRef] [PubMed]

49. Diveki, Z.; Salanki, K.; Balazs, E. The necrotic pathotype of the cucumber mosaic virus (CMV) ns strain is solely determined by amino acid 461 of the 1a protein. Mol. Plant Microbe Interact. 2004, 17, 837-845. [CrossRef]

50. Salánki, K.; Gellért, Á.; Náray-Szabó, G.; Balázs, E. Modeling-based characterization of the elicitor function of amino acid 461 of cucumber mosaic virus 1a protein in the hypersensitive response. Virology 2007, 358, 109-118. [CrossRef] [PubMed]

51. Kang, W.H.; Seo, J.K.; Chung, B.N.; Kim, K.H.; Kang, B.C. Helicase domain encoded by cucumber mosaic virus RNA1 determines systemic infection of Cmr1 in pepper. PLoS ONE 2012, 7, e43136. [CrossRef] [PubMed]

52. Seo, J.K.; Kwon, S.J.; Choi, H.S.; Kim, K.H. Evidence for alternate states of cucumber mosaic virus replicase assembly in positive-and negative-strand RNA synthesis. Virology 2009, 383, 248-260. [CrossRef] [PubMed] 
53. Fujisaki, K.; Hagihara, F.; Azukawa, Y.; Kaido, M.; Okuno, T.; Mise, K. Identification and characterization of the SSB1 locus involved in symptom development by spring beauty latent virus infection in Arabidopsis thaliana. Mol. Plant Microbe Interact. 2004, 17, 967-975. [CrossRef] [PubMed]

54. Chen, H.; Adam Arsovski, A.; Yu, K.; Wang, A. Deep sequencing leads to the identification of eukaryotic translation initiation factor $5 \mathrm{~A}$ as a key element in Rsv1-mediated lethal systemic hypersensitive response to soybean mosaic virus infection in soybean. Mol. Plant Pathol. 2017, 18, 391-404. [CrossRef]

55. Kim, B.M.; Suehiro, N.; Natsuaki, T.; Inukai, T.; Masuta, C. The P3 protein of turnip mosaic virus can alone induce hypersensitive response-like cell death in Arabidopsis thaliana carrying TuNI. Mol. Plant Microbe Interact. 2010, 23, 144-152. [CrossRef]

56. Hajimorad, M.; Eggenberger, A.; Hill, J. Loss and gain of elicitor function of soybean mosaic virus G7 provoking Rsv1-mediated lethal systemic hypersensitive response maps to P3. J. Virol. 2005, 79, 1215-1222. [CrossRef] [PubMed]

57. Komatsu, K.; Hashimoto, M.; Ozeki, J.; Yamaji, Y.; Maejima, K.; Senshu, H.; Himeno, M.; Okano, Y.; Kagiwada, S.; Namba, S. Viral-induced systemic necrosis in plants involves both programmed cell death and the inhibition of viral multiplication, which are regulated by independent pathways. Mol. Plant Microbe Interact. 2010, 23, 283-293. [CrossRef]

58. Hashimoto, M.; Komatsu, K.; Iwai, R.; Keima, T.; Maejima, K.; Shiraishi, T.; Ishikawa, K.; Yoshida, T.; Kitazawa, Y.; Okano, Y. Cell death triggered by a putative amphipathic helix of radish mosaic virus helicase protein is tightly correlated with host membrane modification. Mol. Plant Microbe Interact. 2015, 28, 675-688. [CrossRef] [PubMed]

59. Chen, P.; Buss, G.; Roane, C.; Tolin, S. Inheritance in soybean of resistant and necrotic reactions to soybean mosaic virus strains. Crop Sci. 1994, 34, 414-422. [CrossRef]

(C) 2020 by the authors. Licensee MDPI, Basel, Switzerland. This article is an open access article distributed under the terms and conditions of the Creative Commons Attribution (CC BY) license (http://creativecommons.org/licenses/by/4.0/). 